Research Article

\title{
Effect of Powder Size on Microstructure and Mechanical Properties of 2A12Al Compacts Fabricated by Hot Isostatic Pressing
}

\author{
Xina Huang $\mathbb{D},{ }^{1}$ Lihui Lang, ${ }^{1}$ Gang Wang, ${ }^{1}$ and Sergei Alexandrov $\mathbb{C}^{1,2}$ \\ ${ }^{1}$ School of Mechanical Engineering and Automation, Beihang University, Beijing 100191, China \\ ${ }^{2}$ Institute for Problems in Mechanics, Russian Academy of Sciences, Moscow 119526, Russia \\ Correspondence should be addressed to Xina Huang; huangxina@126.com
}

Received 8 December 2017; Revised 11 February 2018; Accepted 27 February 2018; Published 27 March 2018

Academic Editor: Hongchao Kou

Copyright (c) 2018 Xina Huang et al. This is an open access article distributed under the Creative Commons Attribution License, which permits unrestricted use, distribution, and reproduction in any medium, provided the original work is properly cited.

This paper studied the effects of powder size on densification, microstructure, and mechanical properties of the hot isostaticpressed 2A12 aluminum alloy powder compact. The results show that the near-fully dense powder compact can be successfully achieved and the smaller the powder is, the higher the relative density is. In addition, as the powder size decreases, the precipitated phases in the powder compact change from continuously point-like distribution at the junctions among powder particles to the concentrated distribution at the three-way intersections. Compared with the large powder, the tensile strength, yield strength, and elongation of the compact with the small powder were improved by $14 \%, 30.8 \%$, and $48.6 \%$, respectively.

\section{Introduction}

$2 \mathrm{~A} 12$ aluminum alloy (2A12Al) has low density, high specific strength, and good corrosion resistance, which makes it widely used for the structural components in aeronautics and astronautics [1].

The near-net shaping (NNS) technology has attracted widespread interests. It is considered as a reliable and low-cost material forming process. It has great potential to form the parts with complicated internal cavities, which are difficult to be fabricated by traditional methods such as forging, machining, and so on. The NNS technology is composed of several methods: powder injection molding (PIM), hot isostatic pressing (HIP), powder forging $(\mathrm{PF})$, and cold isostatic pressing (CIP)/sintering $[2,3]$. Usually, the products fabricated by PIM have inferior mechanical properties than those using other NNS technologies [4]. Higher mechanical strength can be obtained through PF, but this method is restricted to the large-scale components. HIP is an appropriate forming process for components with large and complex shapes. In addition, the HIPed parts have a finer and more homogeneous microstructure than the parts formed by other NNS technologies, which leads to an enhancement of the mechanical properties $[5,6]$.
The mechanical properties of HIPed parts are influenced by the densification of the metal powder. The densification process includes three main mechanisms: powder compaction and rearrangement, plastic deformation, and diffusion creep [7-9]. These densification mechanisms are significantly affected by the size and shape of the powder [10]. Longrasso and Koss investigated the influence of Ti powder shape on densification during HIP [8]. In addition, many papers studied the effects of matrix powder size on densification, hardness, microstructure, and wear resistance of composites $[7,11,12]$. However, to the authors' best knowledge, few studies have focused on the effect of monolithic aluminum alloy powder size on densification. Therefore, the aim of this work is to investigate the influence of $2 \mathrm{~A} 12 \mathrm{Al}$ powder size on densification behavior, microstructure, and mechanical properties of powder compacts prepared using HIP.

\section{Experimental Procedures}

2.1. Original Material. Nitrogen gas-atomized $2 \mathrm{~A} 12 \mathrm{Al}$ powder with different average sizes of $195 \mu \mathrm{m}, 124 \mu \mathrm{m}$, and $35 \mu \mathrm{m}$ was used as the original material and defined as powders 1,2, and 3, respectively. They were supplied by ARI 
TABLE 1: Basic characteristics of the powder.

\begin{tabular}{|c|c|c|c|c|c|}
\hline \multirow{2}{*}{ Alloy powders } & \multicolumn{3}{|c|}{ Powder size $(\mu \mathrm{m})$} & \multirow{2}{*}{ Apparent density (\%) } & \multirow{2}{*}{$W(\mathrm{O})(\%)$} \\
\hline & $D_{10}$ & $D_{50}$ & $D_{90}$ & & \\
\hline Powder 1 & 131 & 195 & 292 & 62.74 & 0.12 \\
\hline Powder 2 & 85 & 124 & 174 & 64.30 & 0.15 \\
\hline Powder 3 & 14 & 35 & 67 & 69.96 & 0.26 \\
\hline
\end{tabular}

Forster (Beijing) Technology Development Co., Ltd. in China. The powder size, apparent density, and oxygen content are listed in Table 1 . Among them, $D_{10}$ indicates that the powder size smaller than the $D_{10}$ corresponding size accounts for $10 \% . D_{50}$ usually represents the average size of powders. $D_{90}$ shows that the powder size smaller than the $D_{90}$ corresponding size accounts for $90 \%$. The small powders with high surface energy are prone to be contaminated, resulting in a high oxygen content [13]. The chemical composition of the $2 \mathrm{~A} 12 \mathrm{Al}$ powder is given in Table 2 .

Figure 1 shows the morphologies and the particle size distribution of powders. The powders are nearly spherical in shape, and the size of the powders 1,2, and 3 is between 131 and $292 \mu \mathrm{m}, 85$ and $174 \mu \mathrm{m}$, and 14 and $67 \mu \mathrm{m}$, respectively. It can be found that there are plenty of satellite particles in the small powders (no. 3; Figure 1(c)), which can be attributed that metal liquid was broken into small droplets under the impact force. Compared with the large droplets, small droplets were formed more per unit time. The greater surface tension and undercooling gave rise to the earlier solidification of small droplets than large droplets. The firstly solidified small droplets moved with a high speed and then collided with large droplets, resulting in the cold welding. The small droplets attached to the surface of large ones form the tiny satellite particles. These satellite particles can be filled into the gap between large powders, giving rise to a higher apparent density of powder 3.

2.2. HIP Process. Firstly, $2 \mathrm{~A} 12 \mathrm{Al}$ powders were filled into a 1060 pure $\mathrm{Al}(1060 \mathrm{Al})$ circular cylinder capsule with $60 \mathrm{~mm}$ internal diameter, $120 \mathrm{~mm}$ height, and $1 \mathrm{~mm}$ wall thickness. The 1060Al capsule was used because it does not react with the original material. Subsequently, the capsule was degassed at a temperature of $400^{\circ} \mathrm{C}$ by an FJ-620 molecular pump until the vacuum degree was $1.0 \times 10^{-4} \mathrm{~Pa}$. And then, hot isostatic pressing was carried out in QIH-15 HIP equipment under the process parameters of $470^{\circ} \mathrm{C}, 130 \mathrm{MPa}$, and $3 \mathrm{~h}$ dwell time. Three samples of each powder size were prepared at least. After HIP, the capsule was removed by machining.

2.3. Microstructure and Mechanical Property. The relative density of powder compacts was measured based on Archimedes' principle, and the high-purity water was used in Archimedes' experiment. In addition, three HIPed specimens for each powder size were taken to carry out the tensile tests on a QJ210 electronic universal testing machine based on GB/T 228-2002 metallic material tensile testing in the ambient temperature. The microstructure and fracture morphology of HIPed 2A12Al powder compacts were observed by a JSM 6010 scanning election microscope (SEM). The element distribution
TABLe 2: Chemical composition of the $2 \mathrm{~A} 12 \mathrm{Al}$ powder (wt.\%).

\begin{tabular}{cccccccccc}
\hline Element & $\mathrm{Al}$ & $\mathrm{Cu}$ & $\mathrm{Mg}$ & $\mathrm{Ti}$ & $\mathrm{Si}$ & $\mathrm{Fe}$ & $\mathrm{Mn}$ & $\mathrm{Zn}$ & Others \\
\hline Content & $\mathrm{Bal}$. & 4.1 & 1.5 & 0.15 & 0.5 & 0.5 & 0.4 & 0.3 & 0.15 \\
\hline
\end{tabular}

was characterized by an energy dispersive spectrometer (EDS, CamScan-3400). Before SEM and EDS, the specimens were sectioned, grounded, and polished. Then, the specimens were etched with the Keller reagent $(1.5 \mathrm{ml} \mathrm{HCl}, 2.5 \mathrm{ml} \mathrm{HNO}, 1 \mathrm{ml}$ $\mathrm{HF}$, and $95 \mathrm{ml}$ distilled $\mathrm{H}_{2} \mathrm{O}$ ).

\section{Results and Discussion}

3.1. The Variation of Dimension and Relative Density. Three samples were prepared using HIP for measuring the density and dimensional variation. Figure 2 shows the averaged relative density and the radial and axial dimensional variation rate of powder compacts with different powder sizes and measurement positions.

It can be found in Figure 2(a) that the near-fully dense powder compact can be successfully obtained by HIP. The smallest relative density is $96.2 \%$ obtained from powders with 131-292 $\mu \mathrm{m}$ size, which is higher than that prepared by traditional pressing or sintering (95\%) [14]. The relative density increases with the decrease of powder size, which is similar to the results reported by Barringer and Bowen [15], and the maximum relative density of $97.6 \%$ is obtained when the powder size is between 14 and $67 \mu \mathrm{m}$. At the beginning of HIP, there is a large amount of voids among loose powders with a contact of point-to-point. With the increase of pressure, the loose powders translate or rotate and become close to each other. Besides that, the bridges among the powders collapse. Therefore, the powder particle rearrangement is the main densification mechanism [16, 17]. With the further increase of pressure, the normal stress on the powder surface increases and the yield stress of powder particles decreases with the increase of temperature. When the normal stress exceeds the yield stress, the plastic deformation of powder particles begins to occur. At this time, the plastic deformation of powders becomes the dominant densification mechanism. With the HIP process being carried on, the plastic deformation of powders and the friction among them are increased. Even if the temperature and pressure increase, the movement of powders is still restricted $[18,19]$. The smaller the powder is, the easier the plastic deformation is and the better the densification is. Following rearrangement and plastic deformation, the previous interconnected voids are independent of each other and dispersed uniformly in the powder compact. In addition, the powder compact already has a certain density. The 


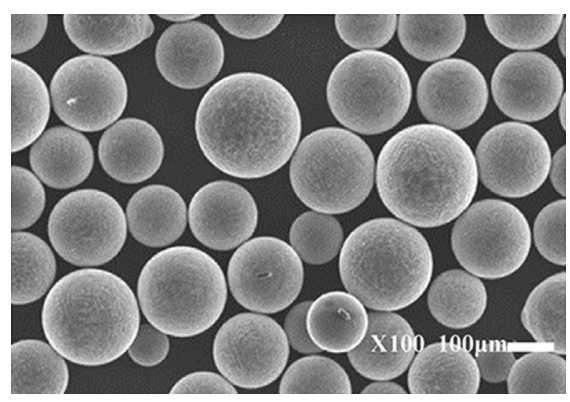

(a)

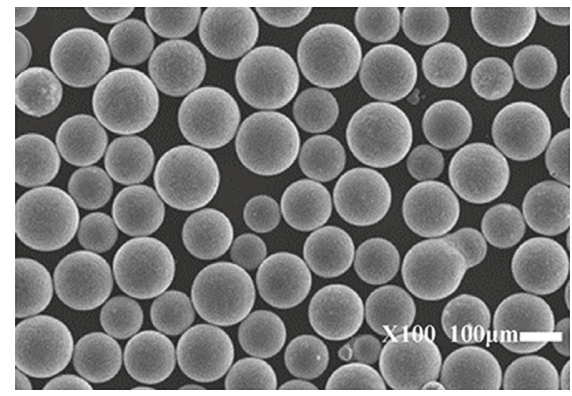

(c)

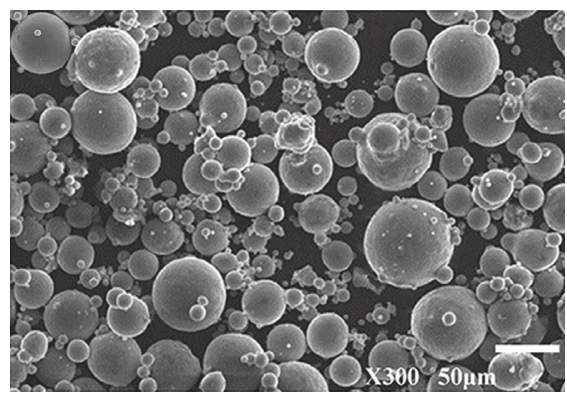

(e)

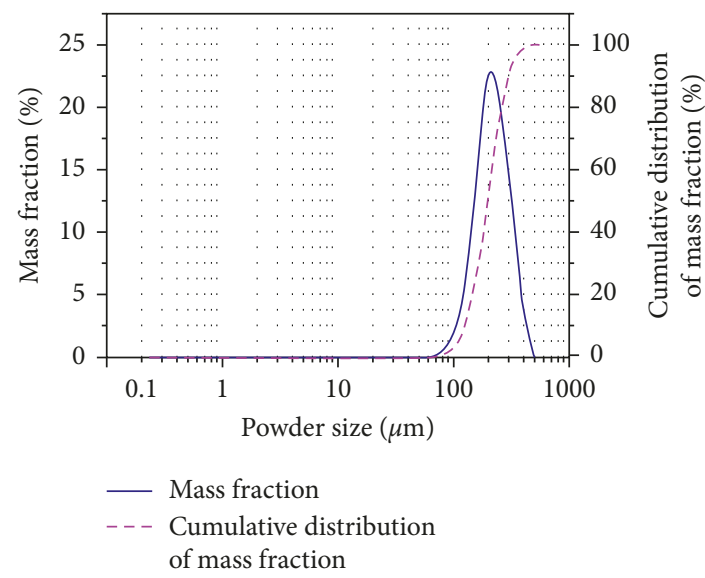

(b)

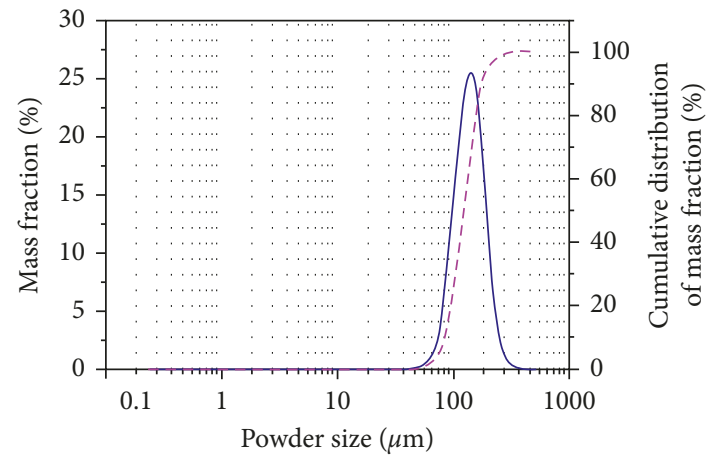

- Mass fraction

Cumulative distribution

of mass fraction

(d)

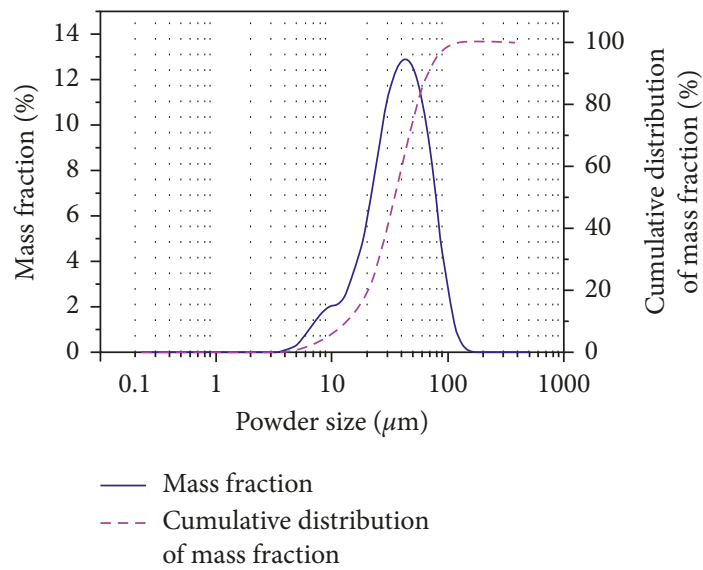

(f)

Figure 1: The morphologies of the powders 1 (a), 2 (b), and 3 (c).

voids are continuously spheroidized under the driven of the surface energy. Therefore, the void size decreases and the contact area of powders increases. With the occurrence of the spheroidization process, the number and size of the voids decrease and the relative density increases. The densification is mainly achieved by the diffusion of individual atoms or voids and the creep of the powder particles. The smaller the powder is, the easier the spheroidization is and the better the densification is. Therefore, the smaller powder has the better densification and the higher relative density.

The change in relative density gives rise to the dimensional variation. As shown in Figure 2(b), the negative value indicates that the powder compact shrinks in both radial and axial directions during HIP. The trends of the dimensional shrinkage 


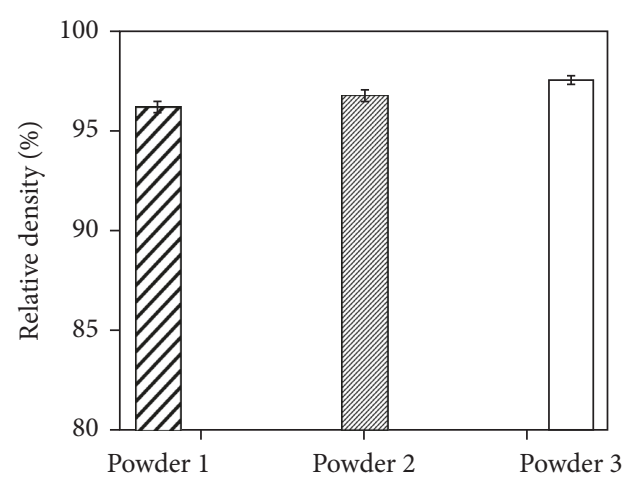

(a)

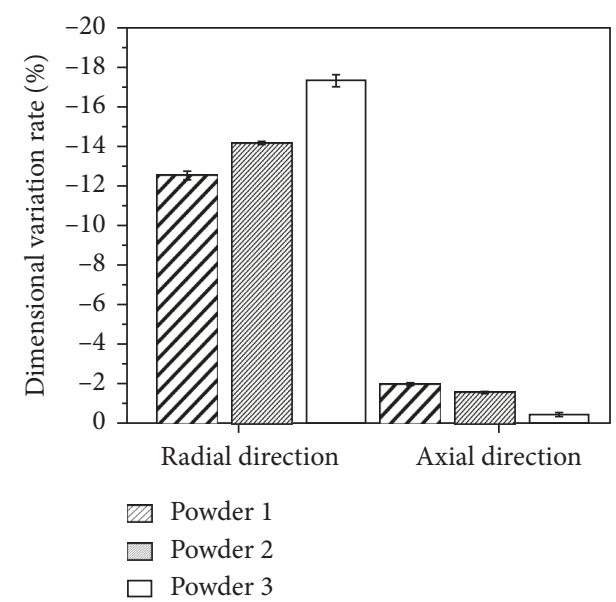

(b)

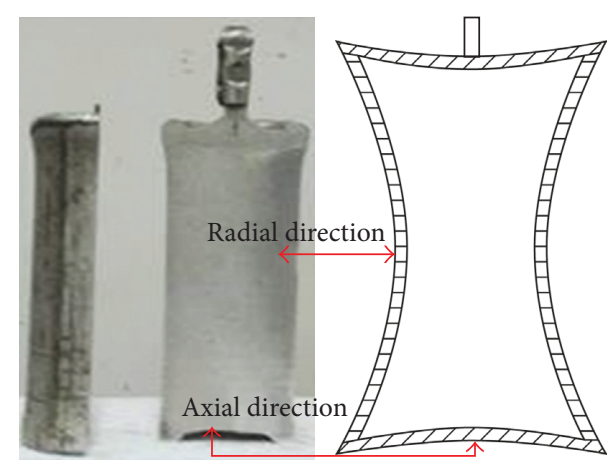

(c)

FIgURE 2: The relative density (a), the radial and axial dimensional variation rate (b), and the radial and axial direction dimensional measurement position (c).

and relative density are consistent. The radial dimensional shrinkage rate increased distinctly from $12.6 \%$ to $17.4 \%$ with the decrease of powder size, while the axial dimensional variation rate decreased slightly from $2.0 \%$ to $0.5 \%$ (Figure 2 (b)). The increase in the radial dimensional shrinkage and the decrease in the axial dimensional variation rate are more obvious with the decrease of powder size, which is because the apparent density is higher and the particle gaps are smaller in the powder compact with small powders (powder 3 ) than that with large powders (powders 1 and 2). With the radial dimensional shrinkage, the powder compact reaches the dense state quickly, which might prevent the axial dimensional variation.

Previous research indicated that radial and axial pressure of the cylinder part is different during HIP, as follows [20]:

$$
\begin{aligned}
& P_{\mathrm{r}}=\frac{P(2 r L)}{2 t L}=\frac{P r}{t}, \\
& P_{\mathrm{a}}=\frac{P\left(\pi r^{2}\right)}{2 \pi r t}=\frac{P r}{2 t},
\end{aligned}
$$

where $P_{\mathrm{r}}$ and $P_{\mathrm{a}}$ are the radial and axial pressure; $P$ is the applied external pressure; and $L, r$, and $t$ are the height, radius, and thickness of the capsule, respectively. According to (1) and (2), the radial pressure is twice the axial pressure; therefore, the axial dimensional variation rate is smaller than the radial. In addition, the upper cover was welded with the cylinder, the rigidity of the welding seam was large, and the solder was accumulated at the welding, leading to a small axial dimensional variation rate.

3.2. Microstructure. Figure 3 shows the micrographs of powder compacts with three different powder sizes after HIP. No obvious internal voids are observed, indicating that the near-fully dense powder compacts are achieved. Prior particle boundary (PPB) of powders was formed because of a large amount of second-phase particles existing at the powder boundaries and can be clearly seen in all compacts. In powders 1 and 2, the powder size is large and uniform; as a consequence, the PPB of each powder was retained in the final compacts, and the precipitated phases (as seen in Figures 3(a) and 3(b)) were distributed at the powder particle boundaries in the continuous point-like form. However, in powder 3 (Figure 3(c)), the PPB of satellite particles almost disappeared, whereas the $\mathrm{PPB}$ of larger particles was apparent, which shows that the precipitated phases were heavily distributed at the three-way intersections among powder particles, instead of the continuously point-like form at the junctions. In addition, coarse precipitated phases can be found at the three-way intersections, which are composed of $\mathrm{Al}, \mathrm{Cu}, \mathrm{Mg}$, and $\mathrm{O}$ elements (Figure 3(d)). The $\mathrm{Cu}$ content of the original material is much lower than precipitated phases at the three-way intersections. Therefore, it can be deducted that $\mathrm{Cu}$ in the original powder diffused and aggregated at the intersections, resulting in the formation of $\mathrm{Al}-\mathrm{Cu}-\mathrm{Mg}$ precipitated phases, which is similar to the results in [15].

It is noted that the $\mathrm{PPB}$ tended to be straight and the angle between boundaries was near $120^{\circ}$ after HIP (vertex of Figure 3(b)) In light of the observation above, it is suggested that the deformation law of the powder under high temperature and pressure is similar to the grain growth law, that is, the grain boundary tends to be straight to reduce the surface area and surface energy. Moreover, the small particles were annexed by adjacent large particles during boundary migration. The angle between boundaries tended to migrate closer to $120^{\circ}$, which is similar to the results in [21]. Nevertheless, the polygonal particles would gradually shrink or grow until the grain size is six. At this time, the interface is in equilibrium, the particles no longer move, and 


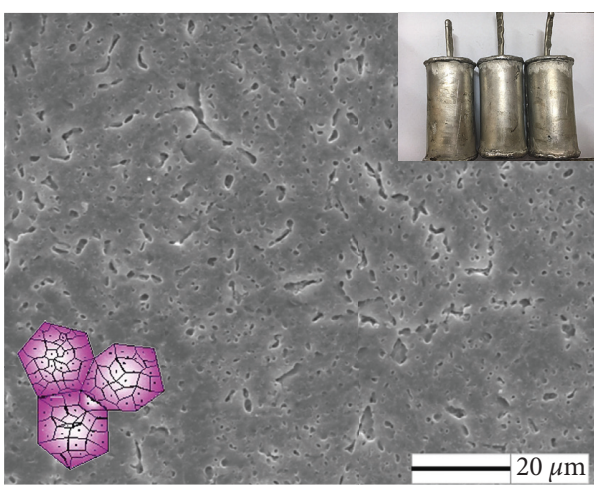

(a)

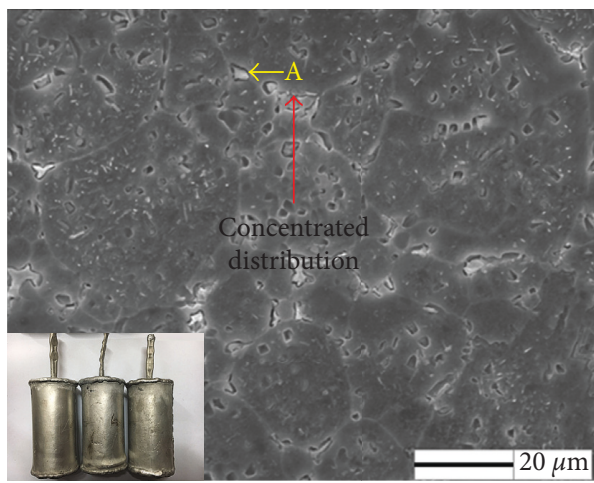

(c)

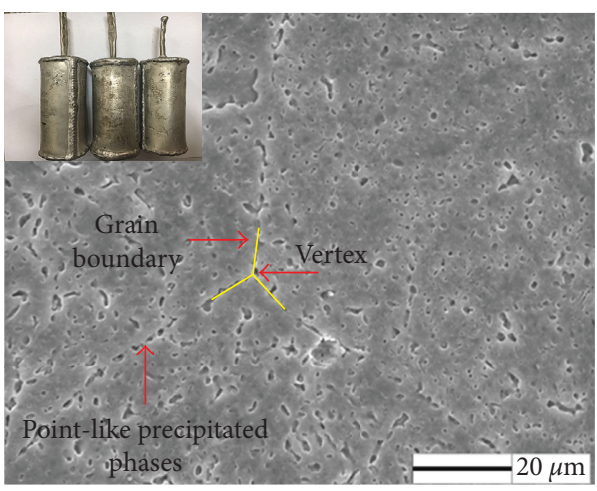

(b)

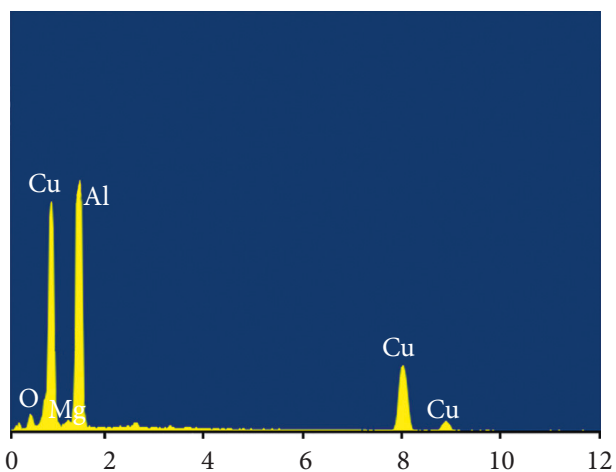

(d)

FIGURE 3: The micrographs of the powder compacts (a) 1, (b) 2, and (c) 3 and (d) the EDS map of point A in (c).

TABLE 3: Mechanical properties of the 2A12Al powder.

\begin{tabular}{lccc}
\hline Alloy powders & Tensile strength $R_{m}(\mathrm{MPa})$ & Yield strength $R_{p 0.2}(\mathrm{MPa})$ & Elongation A $(\%)$ \\
\hline 1 & 265 & 182 & 1.8 \\
2 & 284 & 191 & 2 \\
3 & 308 & 263 & 3.5 \\
\hline
\end{tabular}

the edges are straight with an angle of $120^{\circ}$ [21]. In powder 3 , the large particles contact with each other firstly and then small particles. In addition, the overall temperature of small particles was higher than that of large ones [22], and the plasticity was better. In the further forming process, a majority of the stress among large particles was undertaken by small particles. The deformation of large particles became slow and even stopped, which is similar to the rigid movement of the rigid body. The deformation of small particles promoted the large-scale movement of particles [23]. Therefore, the particle boundary deformation of powder 3 was severe, and part of the small particles even fused together. For the powders 1 and 2, the shape is more uniform and the size is larger than powder 3 , resulting in a more difficult particle rearrangement [24]. Hence, the relative density of powder 3 is higher than that of the powders 1 and 2, which is consistent with the results of relative density measurement.

3.3. Mechanical Properties of 2 A12 Compacts after HIP. Table 3 shows the variation of mechanical properties of the samples fabricated with the three powder sizes. With the decrease of powder size, the ultimate tensile strength, proof strength of plastic extension, and elongation of powder compacts after HIP increased from $265 \mathrm{MPa}$ to $308 \mathrm{MPa}$, from $182 \mathrm{MPa}$ to $263 \mathrm{MPa}$, and from $1.8 \%$ to $3.5 \%$, respectively. The precipitated phases were distributed at the junctions in the continuous uniform point-like form in the powders 1 and 2 . The effective diffusion connection could not be formed, which would have a deleterious effect on the mechanical properties. However, the higher densification and the finer PPB of small powders are favorable for forming a sound bonded interface, which improves the mechanical properties. The tensile strength, yield strength, and elongation increased by $14 \%$, $30.8 \%$, and $48.6 \%$, respectively. Besides, the oxygen content of powder 3 was higher than that of the powders 1 and 2. Such interstitial atoms may act as the obstacles to the dislocation motions; as a result, the strength would be improved with the decrease of powder size [21].

Figure 4 is the fracture morphology of powder compact 1 (Figure 4(a)) and powder compact 3 (Figure 4(b)). The fracture morphology of powder compact 2 is similar to powder 


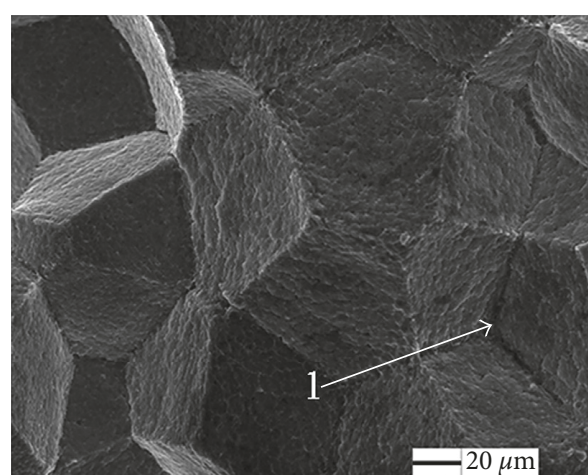

(a)

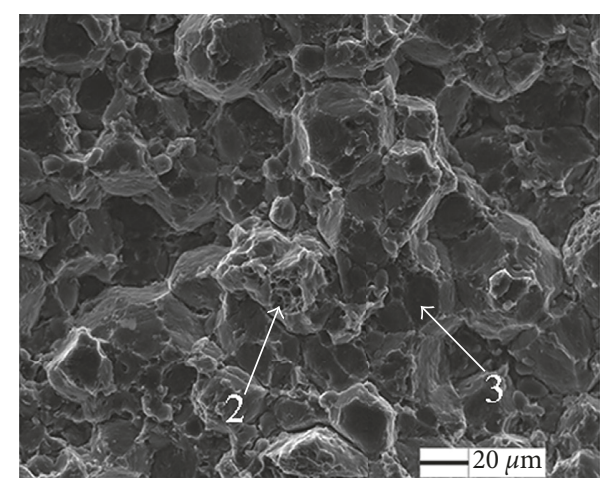

(b)

FIgURE 4: The fracture morphologies of the powder compacts 1 and 2 (a) and 3 (b).

compact 1 . In the powders 1 and 2, the fracture only occurred at the interfaces among particles (arrow 1 in Figure 4(a)); therefore, the fracture feature can be deduced as brittle. In powder 3, dimples appeared in some areas (arrow 2 in Figure 4(b)), indicating the ductile fracture characteristic, which is beneficial for improving the plasticity of the powder compact. In addition, the alloy element precipitation of powder 3 was embedded in the interior of particles (arrow 3 in Figure 4(b)), enhancing the pinning effect and preventing dislocation movement, which would help to increase the strength.

\section{Conclusions}

The following conclusions can be drawn from this study:

(1) Near-fully dense 2A12Al compacts by HIP could be successfully achieved. The maximum relative density was $97.6 \%$, which was obtained with the finest powder. Moreover, higher relative density was accompanied with larger radial and smaller axial dimensional variation rates.

(2) The PPB of large powders tended to be straight, and the angle between boundaries was near $120^{\circ}$ after HIP. However, the PPB of small powders underwent larger deformation, some small particles even fused together, and the PPB of satellite particles almost disappeared.

(3) With the decrease of powder size, the precipitated phase changed from continuous point-like distribution at the junctions to the concentrated distribution in three-way intersection of particles, which made the diffusion bonding of interface tighter and was beneficial to improve the tensile strength, yield strength, and elongation.

(4) The fracture mechanism of the powder compact with the large powder is brittle fracture, while the plastic fracture characteristic can be found in the powder compact with the small powder.

\section{Conflicts of Interest}

The authors declare that they have no conflicts of interest.

\section{References}

[1] J. Yan, X. Y. Zeng, M. Gao, J. Lai, and T. X. Lin, "Effect of welding wires on microstructure and mechanical properties of $2 \mathrm{~A} 12$ aluminum alloy in $\mathrm{CO}_{2}$ laser-MIG hybrid welding," Applied Surface Science, vol. 255, no. 16, pp. 7307-7373, 2009.

[2] D. L. Zhang, S. Raynova, V. Nadakuduru, P. Cao, B. Gabbitas, and B. Robinson, "Consolidation of titanium, and Ti-6Al-4V alloy powders by powder compact forging," Materials Science Forum, vol. 618-619, pp. 513-516, 2009.

[3] L. Wang, Z. B. Lang, and H. P. Shi, "Properties and forming process of prealloyed powder metallurgy Ti-6Al-4V alloy," Transactions of Nonferrous Metals Society of China, vol. 17, pp. s639-s643, 2007.

[4] R. M. German, "Progress in titanium metal powder injection molding," Materials, vol. 6, no. 12, pp. 3641-3662, 2013.

[5] Y. M. Kim, E. P. Kim, Y. B. Song, S. H. Lee, and Y. S. Kwon, "Microstructure and mechanical properties of hot isostatically pressed Ti-6Al-4V alloy," Journal of Alloys and Compounds, vol. 603, pp. 207-212, 2014.

[6] K. T. Kim and H. C. Yang, "Densification behavior of titanium alloy powder under hot isostatic pressing," Powder Metallurgy, vol. 44, no. 1, pp. 41-46, 2001.

[7] E. A. Diler, A. Ghiami, and R. Ipek, "Effect of high ratio of reinforcement particle size to matrix powder size and volume fraction on microstructure, densification and tribological properties of $\mathrm{SiC}_{\mathrm{p}}$ reinforced metal matrix composites manufactured via hot pressing method," International Journal of Refractory Metals and Hard Materials, vol. 52, pp. 183-194, 2015.

[8] B. K. Lograsso and D. A. Koss, "Densification of titanium powder during hot isostatic pressing," Metallurgical Transactions A, vol. 19, no. 7, pp. 1767-1773, 1998.

[9] E. Arzt, "The influence of an increasing particle coordination on the densification of spherical powders," Acta Metallurgica, vol. 30, no. 10, pp. 1883-1890, 1982.

[10] D. Bouvard, "Densification behavior of mixtures of hard and soft powders under pressure," Powder Technology, vol. 111, no. 3, pp. 231-239, 2000.

[11] T. Fan, C. L. Xiao, Y. R. Sun, and H. B. Li, "Microstructure and properties of $\mathrm{SiC}$ particle reinforced aluminum matrix composites by powder metallurgy method," Applied Mechanics and Materials, vol. 457-458, pp. 131-134, 2014.

[12] E. K. Omyma and A. Fathy, "Effect of SiC particle size on the physical and mechanical properties of extruded $\mathrm{Al}$ matrix nanocomposites," Materials \& Design, vol. 54, pp. 348-353, 2014. 
[13] Y. M. Kim, E. P. Kim, J. W. Noh, S. H. Lee, Y. S. Kwon, and I. S. Oh, "Fabrication and mechanical properties of powder metallurgy tantalum prepared by hot isostatic pressing," International Journal of Refractory Metals and Hard Materials, vol. 48, pp. 211-216, 2015.

[14] C. Padmavathi and A. Upadhyaya, "Sintering behavior and mechanical properties of $\mathrm{Al}-\mathrm{Cu}-\mathrm{Mg}-\mathrm{Si}-\mathrm{Sn}$ aluminum alloy," Transactions of the Indian Institute of Metals, vol. 64, no. 4-5, pp. 345-357, 2011.

[15] E. A. Barringer and H. K. Bowen, "Effects of particle packing on the sintered microstructure," Applied Physics A Solids and Surfaces, vol. 45, no. 4, pp. 271-275, 1988.

[16] M. M. Goudarzi and F. Akhlaghi, "Effect of nanosized SiC particles addition to $\mathrm{CP} \mathrm{Al}$ and $\mathrm{Al}-\mathrm{Mg}$ powders on their compaction behavior," Powder Technology, vol. 245, pp. 126-133, 2013.

[17] H. R. Hafizpour, A. Simchi, and S. Parvizi, "Analysis of the compaction behavior of $\mathrm{Al}-\mathrm{SiC}$ nanocomposites using linear and non-linear compaction equations," Advanced Powder Technology, vol. 21, no. 3, pp. 273-278, 2010.

[18] P. J. Denny, "Compaction equations: a comparison of the Heckel and Kawakita equations," Powder Technology, vol. 127, no. 2, pp. 162-172, 2002.

[19] S. Mahdavi and F. Akhlaghi, "Effect of SiC content on the processing, compaction behavior, and properties of Al6061/SiC/Gr hybrid composites," Journal of Materials Science, vol. 46, no. 5, pp. 1502-1511, 2011.

[20] D. P. Delo and H. R. Piehler, "Early stage consolidation mechanisms during hot isostatic pressing of Ti-6Al-4V powder compacts," Acta Materialia, vol. 47, no. 9, pp. 2841-2852, 1999.

[21] N. K. Li, G. Ling, and B. Nie, Aluminum Alloy Material and Heat Treatment Technology, Vol. 287, Metallurgical Industry Press, Beijing, China, 2012.

[22] G. H. Xu, X. H. Zhang, C. M. Zhao, L. Wang, and Z. W. Yin, "Microstructure of PM TC11 alloy and its effect on mechanical behavior," Aerospace Materials \& Technology, vol. 3, pp. 110-113, 2013.

[23] Y. E. Bing, R. M. Matsen, and C. D. David, "Finite-element modeling of titanium powder densification," Metallurgical and Materials Transactions A, vol. 43, no. 1, pp. 381-390, 2012.

[24] K. Kondah, A. Kimura, and R. Watanabe, "Effect of Mg on sintering phenomenon of aluminum alloy powder particle," Powder Metallurgy, vol. 44, no. 2, pp. 161-164, 2001. 


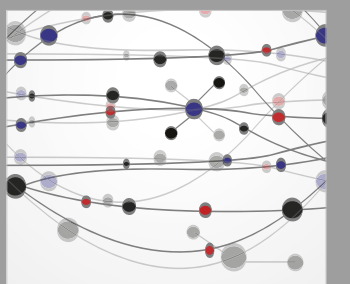

The Scientific World Journal
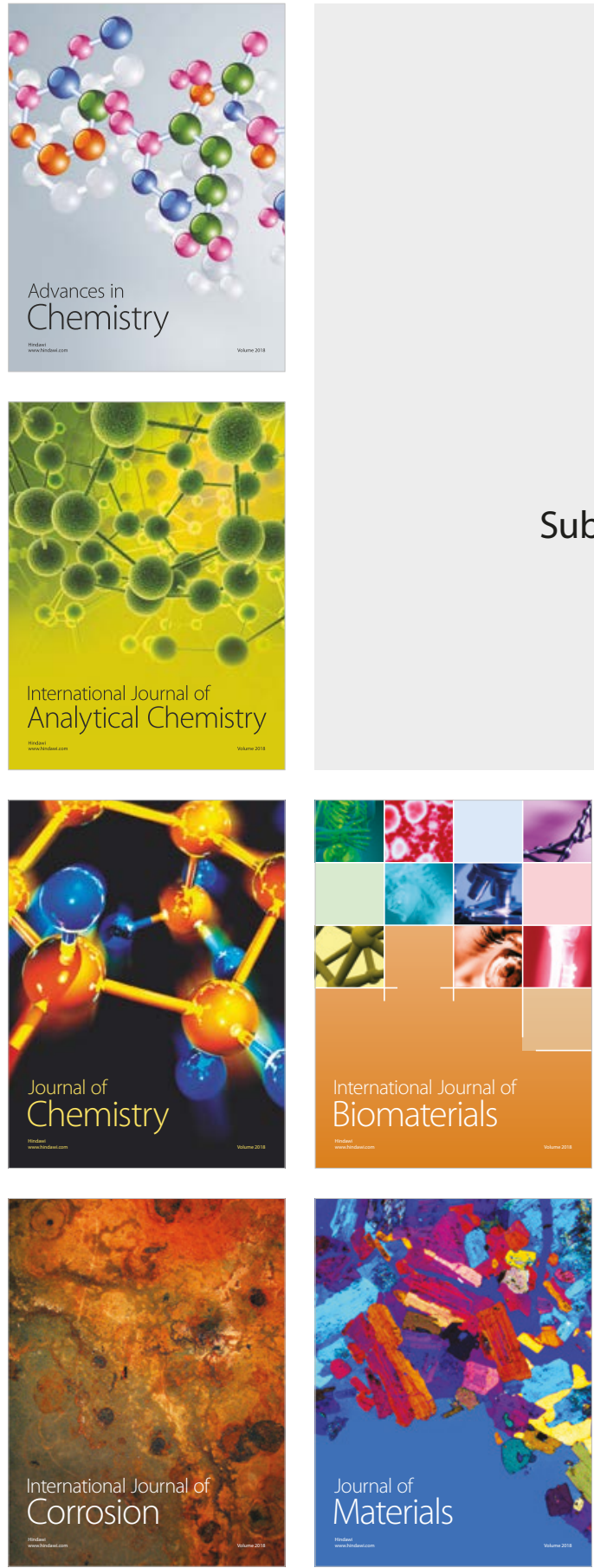

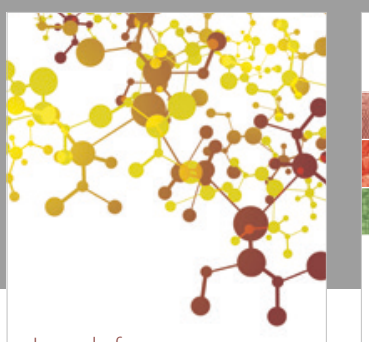

Journal of

Applied Chemistry
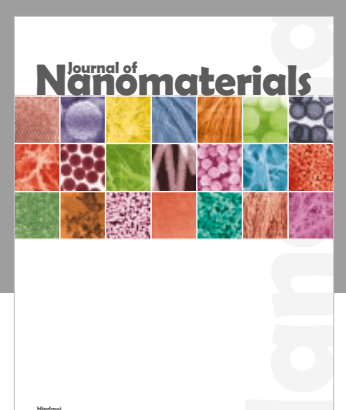

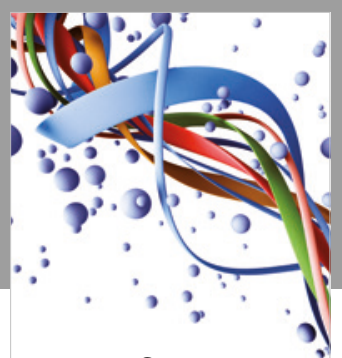

Scientifica

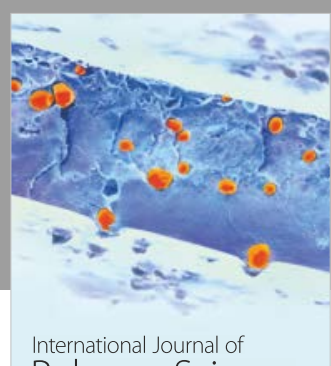

Polymer Science

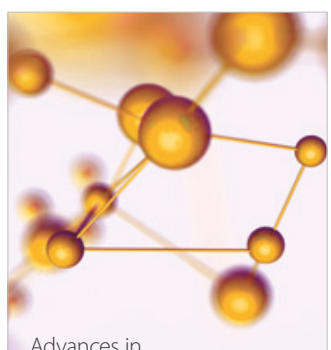

Physical Chemistry
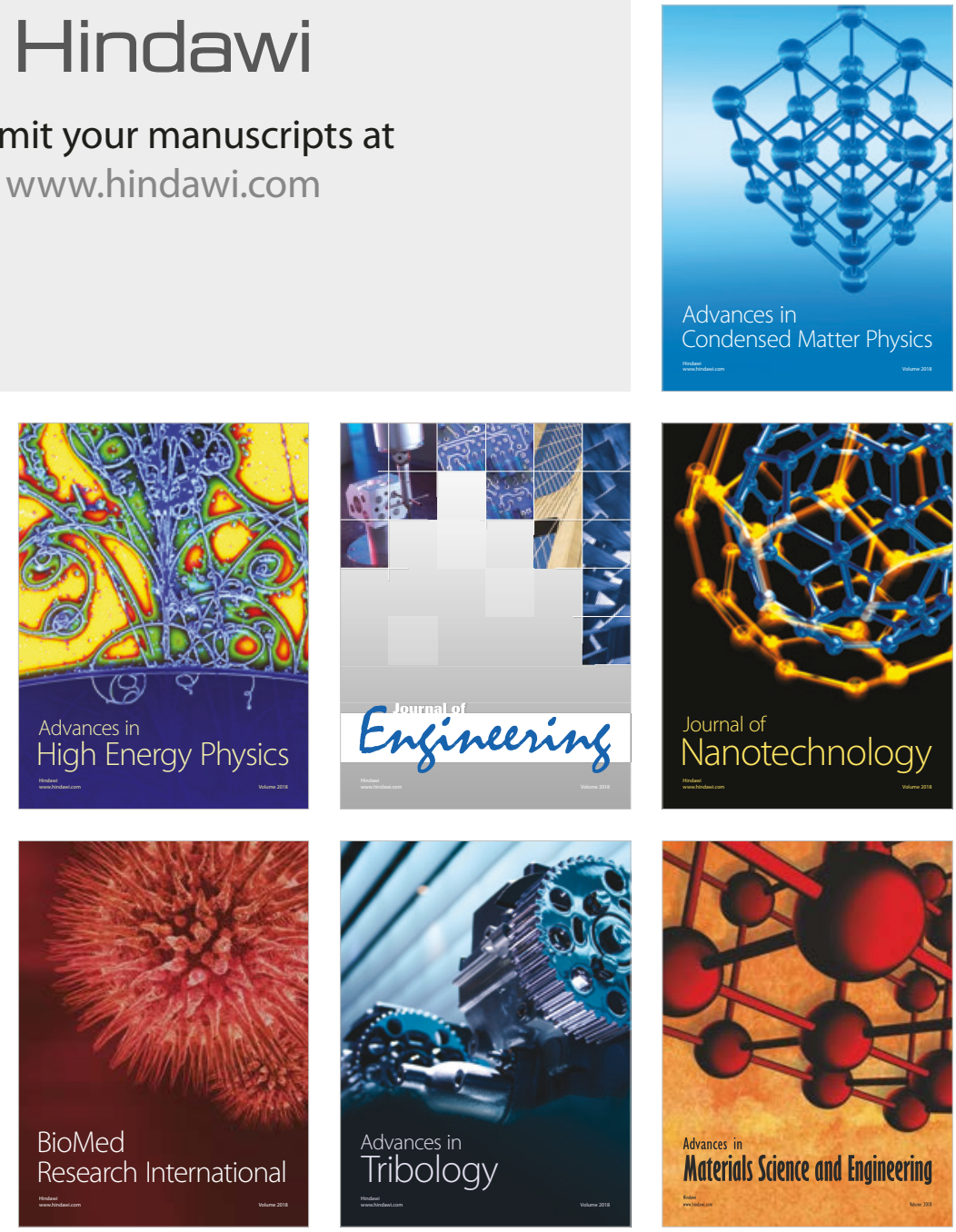